\title{
Sex hormone regulation of survivin gene expression
}

\author{
Nancy H Nabilsi, Russell R Broaddus ${ }^{1}$, Adrienne S McCampbell ${ }^{1}$, Karen H Lu ${ }^{2}$, Henry T Lynch ${ }^{3}$, \\ Lee-may Chen ${ }^{4}$ and David S Loose
}

Department of Integrative Biology and Pharmacology, University of Texas Health Science Center Houston, 6431 Fannin Street, MSB 5.132A, Houston, Texas 77030, USA

Departments of ${ }^{1}$ Pathology and ${ }^{2}$ Gynecologic Oncology, University of Texas MD Anderson Cancer Center, Houston, Texas 77030, USA

${ }^{3}$ Department of Preventive Medicine and Public Health, Creighton University School of Medicine, Omaha, Nebraska, 68131 USA

${ }^{4}$ Department of Gynecologic Oncology, University of California at San Francisco, San Francisco, California, 94143 USA

(Correspondence should be addressed to D S Loose; Email: david.s.loose@uth.tmc.edu)

\begin{abstract}
Survivin (BIRC5) is a cell survival gene that is overexpressed in endometrial cancer and has been implicated to have a physiological role in normal endometrial function. To determine whether survivin gene expression is regulated by reproductive steroid hormones in the human endometrium, RNA was prepared from normal cycling women in the proliferative and secretory phases of the menstrual cycle. RNA was also isolated from 21 endometrial biopsies from premenopausal women at baseline and following 3 months of treatment with depot medroxyprogesterone acetate. Finally, RNA was isolated from endometrial biopsies from ten healthy postmenopausal women participating in a clinical trial of estrogen replacement therapy at baseline and following 6 months of treatment with conjugated equine estrogen. Quantitative RT-PCR analysis was used to determine
\end{abstract}

survivin, insulin-like growth factor binding protein 1 (IGFBP1), Ki67, and IGF1 gene expression levels. Survivin gene expression was highest in the proliferative phase of the menstrual cycle and showed a statistically significant 4-fold increase in expression following chronic treatment with estrogens; this was strongly correlated with increased Ki67, a marker of proliferation. Survivin gene expression decreased $4 \cdot 6$-fold following chronic progestin treatment in the human endometrium. These data suggest that survivin transcript is regulated by estrogens and progestins in the disease-free human endometrium. The data also suggest that survivin transcript may be used as a biomarker of estrogen and progestin treatment efficacy, but validation studies must be conducted to support this conclusion.

Journal of Endocrinology (2010) 207, 237-243

\section{Introduction}

The human endometrium is a dynamic tissue that lines the uterine cavity. It is composed of both epithelial and stromal cells and is cyclically regenerated. The reproductive cycle in human females is driven through neuroendocrine signaling. Both positive and negative feedback loops within the hypothalamus and pituitary control steroid hormone production in the ovaries. Increased estrogen $\left(\mathrm{E}_{2}\right)$ drives the endometrium into the proliferative phase of the cycle. As the cycle progresses, progesterone $\left(\mathrm{P}_{4}\right)$ is secreted by the ovary, which inhibits proliferation and restructures the endometrium into a secretory tissue in anticipation of fertilization. If fertilization does not occur, the endometrium is shed and the local drop in hormone levels reactivates the cycle (Knobil 1972, Bischof et al. 1974). Several lines of evidence suggest that apoptosis also plays a significant role in the normal cycling of the human endometrium (Kokawa et al. 1996, Vaskivuo et al. 2000, Harada et al. 2004).
Survivin (BIRC5) is a member of the inhibitor of apoptosis $(I A P)$ gene family. Survivin has received much attention as a mediator of cell survival due to its dual function in both apoptosis and cell cycle regulation. The pattern of survivin gene expression is distinct from the other IAPs. Survivin is highly expressed during embryonic and fetal development and is overexpressed in virtually all tumor types (Ambrosini et al. 1997, Li \& Altieri 1999, O’Driscoll et al. 2003) including endometrial cancer (Lehner et al. 2002, Takai et al. 2002, Pallares et al. 2005, Nabilsi et al. 2009). In contrast, survivin is negligibly expressed in most highly differentiated adult tissues. It is, however, expressed in the cycling human endometrium (Konno et al. 2000, Tarkowski et al. 2000, Lehner et al. 2002, Fukuda \& Pelus 2006), in the decidua and villus of early pregnant women (Li et al. 2002), and in non-malignant endometrial pathologies such as endometriosis (Tarkowski et al. 2001, Ueda et al. 2002, Goteri et al. 2005, Fujino et al. 2006) and endometrial hyperplasia (Tarkowski et al. 2000, Chen et al. 2009), suggesting that it may play a role in endometrial physiology and pathology. 
Information on survivin function in normal tissues has been limited as survivin knockout mice suffer from embryonic lethality. Animal models have implicated a physiological role for survivin in the murine endometrium, but the precise function of survivin in endometrial tissue is unclear. High expression of survivin has been found in the endometrium of mice exhibiting defective implantation and subsequent pregnancy loss (Garcia et al. 2007, Li et al. 2008). Loss of survivin expression has also been described in the decidua of interleukin-11 receptor $\alpha$ null mice which are infertile due to aberrations in decidualization and trophoblast invasion (Garcia et al. 2007). Studies in endometrial cancerderived Ishikawa cells indicate that silencing of survivin decreases cell proliferation and increases apoptosis via downregulation of cyclin D1 and phospho-retinoblastoma protein and activation of caspase-3 and caspase-8 (Ai et al. 2006).

Since the endometrium is a hormone-responsive tissue, we hypothesized that if survivin is involved in maintaining normal tissue homeostasis, then it may be regulated by reproductive steroid hormones in the normal human endometrium. Studies in hormone-responsive cell lines indicate that survivin transcript and protein levels are increased by $\mathrm{E}_{2}$ treatment (Nakayama et al. 2000, Sayeed et al. 2007), and in Ishikawa cells, the induction is reversed upon treatment with the estrogen receptor antagonist Fulvestrant (Chen et al. 2009). Also in hyperplastic endometria and in Ishikawa cells, survivin protein is decreased by progestin treatment, and in Ishikawa cells, this decrease is reversed by treatment with the $\mathrm{P}_{4}$ receptor antagonist RU486 (Chen et al. 2009). The effects of estrogen and $\mathrm{P}_{4}$ administration on survivin expression in disease-free human endometrium have not been reported.

In this study, we measured survivin gene expression levels in vivo in cycling human endometrium before and after treatment with progestins and in postmenopausal endometrium after treatment with estrogens.

\section{Materials and Methods}

\section{Endometrial samples}

All human tissue samples were obtained from patients under protocols approved by Institutional Review Boards at the University of Texas Health Science Center and MD Anderson Cancer Center. Formalin-fixed, paraffin-embedded (FFPE) sections of human endometrial biopsies were obtained from the Department of Pathology, University of Texas MD Anderson Cancer Center (Houston, TX, USA) from 12 women who underwent biopsy for the clinical evaluation of abnormal vaginal bleeding as previously described (McCampbell et al. 2006). The endometrial samples were classified as proliferative $(n=7)$ or secretory $(n=5)$ according to Noyes criteria (Noyes et al. 1975) after microscopic examination of H\&E-stained slides. For the proliferative phase endometrial biopsies, women ranged in age from 29 to
50 years (mean of $40 \cdot 4$ years), and body mass index (BMI) ranged from $17 \cdot 1$ to $52 \cdot 3 \mathrm{~kg} / \mathrm{m}^{2}$ (mean of $29 \cdot 5 \mathrm{~kg} / \mathrm{m}^{2}$ ). For the secretory phase endometrial biopsies, women ranged in age from 31 to 46 years (mean of $41 \cdot 8$ years), and BMI ranged from $19 \cdot 3$ to $30 \cdot 3 \mathrm{~kg} / \mathrm{m}^{2}$ (mean of $22 \cdot 6 \mathrm{~kg} / \mathrm{m}^{2}$ ). There was no significant difference in the mean age or BMI between women with proliferative or secretory phase endometrium $(P=0 \cdot 6$ and $P=0 \cdot 2$ respectively).

The RNA used for analysis of $\mathrm{P}_{4}$ regulation of survivin gene expression was obtained from healthy cycling women who were enrolled in a chemoprevention trial of depot medroxyprogesterone acetate (DEPO; $150 \mathrm{mg}$ i.m. DEPO, Pharmacia \& UpJohn) for prevention of endometrial cancer. The endometrial biopsies were timed so that they were performed between days 8 and 10 (proliferative phase) of the woman's menstrual cycle. All of the baseline (pre-treatment) endometrial biopsies used in this study were microscopically confirmed by a gynecologic pathologist to be in proliferative phase according to Noyes criteria. The group included women between the ages of 25 and 48 years (mean age $=36 \cdot 8$ years), and mean BMI $=28.4 \mathrm{~kg} / \mathrm{m}^{2}$ (range $19 \cdot 3-48 \cdot 4 \mathrm{~kg} / \mathrm{m}^{2}$ ) with no prior hysterectomy, no history of prior pelvic radiation, no chemotherapy for 2 years, and no use of oral contraceptives or hormones for 4 months prior to initiation of the study. Women also had to have no medical contraindication to use DEPO, including known or suspected pregnancy, undiagnosed vaginal bleeding, active thrombophlebitis or past history of thromboembolic disorders or cerebral vascular disease, gall bladder disease, history of diabetes, coronary artery disease, or a current tobacco smoker age $>35$.

The RNA used for the analysis of estrogen regulation of survivin expression in postmenopausal women was obtained from a randomly selected subset $(n=10)$ of a large group of healthy postmenopausal women $(n=210)$ participating in a clinical trial of estrogen replacement therapy as previously described (Deng et al. 2003, 2005). The group included women between the ages of 44 and 59 years (mean age $=50.7$ years), mean $\mathrm{BMI}=24.4 \mathrm{~kg} / \mathrm{m}^{2}$ (range $19 \cdot 3-28 \cdot 6 \mathrm{~kg} / \mathrm{m}^{2}$ ), mean serum $\mathrm{E}_{2}=9 \cdot 7 \mathrm{pg} / \mathrm{ml}$ (range $1 \cdot 4-19 \cdot 3 \mathrm{pg} / \mathrm{ml}$ ), mean $\mathrm{FSH}=86.3 \mathrm{mIU} / \mathrm{ml}$ (range $51 \cdot 7-148 \cdot 2 \mathrm{mIU} / \mathrm{ml}$ ), and mean prolactin $=7 \cdot 2 \mathrm{ng} / \mathrm{ml}$ (range $3 \cdot 0-24 \cdot 7 \mathrm{ng} / \mathrm{ml}$ ). Endometrial biopsies were obtained at baseline and after 6 months of Premarin $(0.625 \mathrm{mg} /$ day conjugated equine estrogen, Wyeth-Ayerst) treatment. All endometrial biopsies were microscopically examined to confirm the absence of endometrial pathology (hyperplasia or carcinoma). Tissues were frozen in liquid nitrogen and stored at $-80^{\circ} \mathrm{C}$. Frozen tissues were homogenized in TRI Reagent, and RNA was precipitated with isopropanol, applied to RNeasy spin columns (Qiagen), eluted, and treated with RNase-free DNase for $30 \mathrm{~min}$ at $37^{\circ} \mathrm{C}$, followed by heat inactivation at $75^{\circ} \mathrm{C}$ and storage at $-80^{\circ} \mathrm{C}$. RNA was isolated from FFPE tissues as previously described (McCampbell et al. 2006). 


\section{Quantitative real-time $R T-P C R$}

All TaqMan quantitative real-time RT-PCR (QPCR) assays were designed with Primer Express software. The assays were developed, and all reactions were completed at the Quantitative Genomics Core Laboratory (UT-Houston Medical School, Houston, TX, USA). Forty nanograms of RNA from each sample were assayed in triplicate with a fourth reverse transcriptase negative control as previously described (Xie et al. 2007). The results were analyzed using SDS 1.9.1 software (Applied Biosystems, Carlsbad, CA, USA) with SuperROX (BioSearch, Novato, CA, USA) as a reference dye. Transcripts were quantified against a standard curve comprised of five serial log dilutions of known DNA quantity. The mean transcript levels for all assays were normalized to $18 \mathrm{~s}$ rRNA transcript levels of the housekeeping gene. Data are presented as a median ratio of (transcript/18s rRNA). Survivin and 18 s assay sequences have been reported as follows (Nabilsi et al. 2009): insulin-like growth factor binding protein 1 (IGFBP1; NM_000596): 620+GGGACGCCATCAGTACC, 681 -CCATTTTTTGATGTTGGTGAC, $638+$ FAM-ATGATGGCTCGAAGGCTCTCCA-BHQ1; IGF1 (M27544): 187+ TCCAACCCAATTATTTAAGTGCTGC, 278-ACAGCGCCAGGTAGAAGAGA, 227 + FAMAAGGTGAAGATGCACACCATGTCCTCCTC-BHQ1; Ki67 (NM_002417): 3323+AAGTTCACACGGACGTCAG, 3391-GATGCTCTTGCCATCTCC, $3347+$ FAM-ACCACGCACACGCACAGAGAG-BHQ1.

\section{Statistical analysis}

In all cases, we assumed that our data were not normally distributed, and statistical significance was calculated using either paired or unpaired non-parametric $t$-tests as appropriate. Wilcoxon signed-rank test was used to determine significance in matched (paired) samples for both patient treatment groups. A Mann-Whitney $U$ test was used to determine significance from unpaired samples. A Spearman's rank correlation test was used to determine significant correlations between changes in transcript expression. All types of analysis were conducted in GraphPad Prism 5 statistical software (La Jolla, CA, USA), and a $P$ value $<0.05$ was considered significant.

\section{Results}

Survivin $m R N A$ is differentially expressed in the cycling human endometrium

The proliferative and secretory phases of the reproductive cycle in the human endometrium are dominated by $\mathrm{E}_{2}$ and $\mathrm{P}_{4}$ signaling respectively. Previous reports on survivin gene expression in the cycling human endometrium have been conflicting (Konno et al. 2000, Tarkowski et al. 2000, Lehner et al. 2002). To determine whether survivin transcript is physically expressed in the cycling human endometrium,
QPCR analysis was conducted on RNA isolated from proliferative $(n=7)$ and secretory $(n=5)$ phase endometrial biopsies. Survivin gene expression levels were nearly 50 -fold higher in proliferative endometrial biopsies compared to secretory biopsies (median proliferative $=4 \cdot 08$, median secretory $=0 \cdot 08 ; P=0 \cdot 01 ;$ Fig. 1$)$. Since differences between these two phases are largely driven by steroid hormone signaling, we hypothesized that survivin transcript levels are increased in response to $\mathrm{E}_{2}$ and decreased in response to $\mathrm{P}_{4}$ in the human endometrium.

Survivin $m R N A$ levels are decreased in response to $P_{4}$ treatment in the human endometrium

To determine whether endometrial tissue from women treated for 3 months with DEPO responded physiologically to progestin treatment, post treatment biopsies were examined histologically. The presence of microscopic changes associated with non-proliferative endometrium (presence of endometrial stromal cells that are pre-decidualized, characterized by stromal cells with increased eosinophilic cytoplasm and acquisition of an epithelioid shape; presence of secretorytype or inactive endometrial glands) indicated a good response to progestins. Of the 21 post treatment endometrial biopsies, 19 exhibited features consistent with a good response to progestin treatment (Fig. 2a). Two biopsies showed a poor response indicated by the absence of these changes and/or the presence of mitotic figures in the endometrial glands and/or stroma (Fig. 2b).

To determine whether DEPO treatment induced expression of known $\mathrm{P}_{4}$-responsive genes, we measured the transcript levels of IGFBP1, a gene that is strongly expressed in the secretory endometrium and is known to be induced by

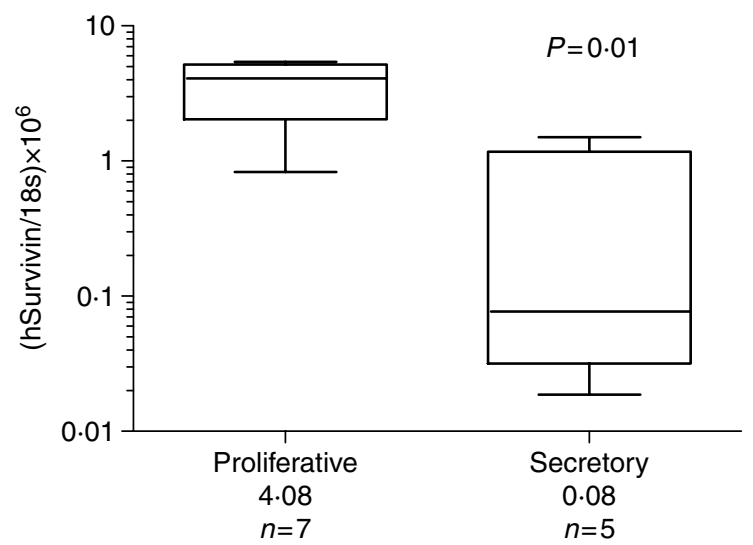

Figure 1 Survivin mRNA is differentially expressed in the cycling human endometrium. RNA samples obtained from endometrial biopsies of women in the proliferative phase $(n=7)$ or secretory phase $(n=5)$ of the reproductive cycle were analyzed by QPCR for survivin. Data are presented as a median ratio of (survivin/ $18 \mathrm{~s}$ rRNA $) \times 10^{6}$. Box denotes $25-75 \%$ distribution, and whiskers denote $10-90 \%$ range. Mann-Whitney unpaired $U$ test was used to determine significance. 

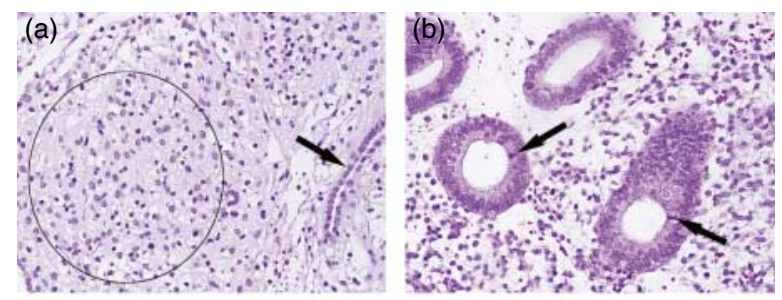

(c)

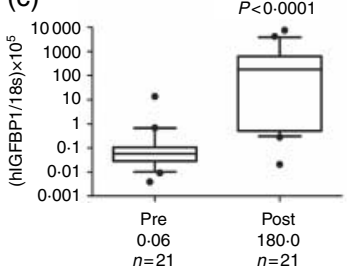

(d)

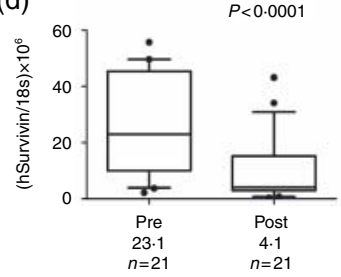

Figure 2 Survivin gene expression is decreased in the human endometrium after progestin treatment. Representative photomicrographs demonstrating examples of a good (a) and poor (b) histological response to progestin treatment. (a) Good progestin treatment response was characterized by the presence of small, inactive appearing endometrial glands composed of a single layer of glandular epithelial cells that are free of mitotic figures (arrow) and stromal cells undergoing pre-decidualization changes (open circle). The pre-decidualized stromal cells have more eosinophilic cytoplasm and are more epithelioid in shape than the usual endometrial stromal cell, which typically has very little cytoplasm and has poorly defined cell borders. (b) A poor progestin response was characterized by the presence of proliferative-type endometrial glands composed of multiple layers of glandular epithelial cells and containing darkly stained mitotic figures (arrows). Note that the proliferative-type endometrial glands in (b) are much larger than the inactive-appearing glands in (a). H\&E, 200×. RNA samples obtained from endometrial biopsies of 21 women at baseline and after 3 months of DEPO treatment were analyzed by QPCR for IGFBP1 (c) and survivin (d). Data are presented as a median ratio of (c) (IGFBP1/18s rRNA) $\times 10^{5}$ or (d) (survivin $/ 18 \mathrm{~s}$ rRNA) $\times 10^{6}$. Box represents $25-75 \%$ distribution, and whiskers represent $10-90 \%$ range. Wilcoxon signed-rank test was used to determine significance. Full colour version of this figure available via http://dx.doi. org/10.1677/JOE-10-0128.

$\mathrm{P}_{4}$ in the endometrium (Bell et al. 1991, Gao et al. 1994a,b). IGFBP1 is a $\mathrm{P}_{4}$-inducible secreted factor that modulates insulin-like growth factor (IGF) bioavailability and functions in concert with IGF proteins to regulate a variety of reproductive processes including menses, puberty, ovulation, decidualization, implantation, and fetal growth (Lane et al. 1994, Richards et al. 1995, Fowler et al. 2000). We observed negligible expression of IGFBP1 in all of the baseline endometrial samples followed by a 3000-fold increase in the median level of mRNA in post treatment endometrial samples indicating successful drug administration (Fig. 2c). Overall, survivin transcript expression decreased $4 \cdot 6$-fold following treatment compared to baseline levels (median pre $=23 \cdot 1$, median post $=4 \cdot 1, n=21, P<0 \cdot 0001$; Fig. $2 \mathrm{~d}$ ). Fold change in survivin did not correlate with change in IGFBP1 $(P=0 \cdot 19)$. If we examine change per individual, the median change in survivin transcript levels following treatment for the good responders is $-3 \cdot 3$-fold $(n=19)$. With only two poor responders, there are insufficient data to draw conclusions regarding survivin in these women (mean fold change $=+0 \cdot 74, n=2$ ).

\section{Survivin levels are increased in response to estrogen treatment} in the human endometrium

QPCR analysis of endometrial biopsies taken at baseline and after 6 months of treatment with estrogens showed a significant 4-fold up-regulation of survivin transcript (median pre $=0 \cdot 65$, median post $=3 \cdot 23, n=10, P=0 \cdot 013$; Fig. 3a). Survivin expression was increased in seven of the ten patients with the remaining three patients showing no change or a small decrease in survivin expression (\#2, \#5, and \#9; Fig. 3b). To confirm induction of estrogen-regulated genes in the endometrial tissue of the women after treatment, we measured the transcript levels of IGF1, a well known estrogen-inducible gene involved in estrogen-mediated endometrial proliferation (Rutanen 1998, Moyano \& Rotwein 2004, McCampbell et al. 2006, Kashima et al. 2009), which we have previously shown to be induced by
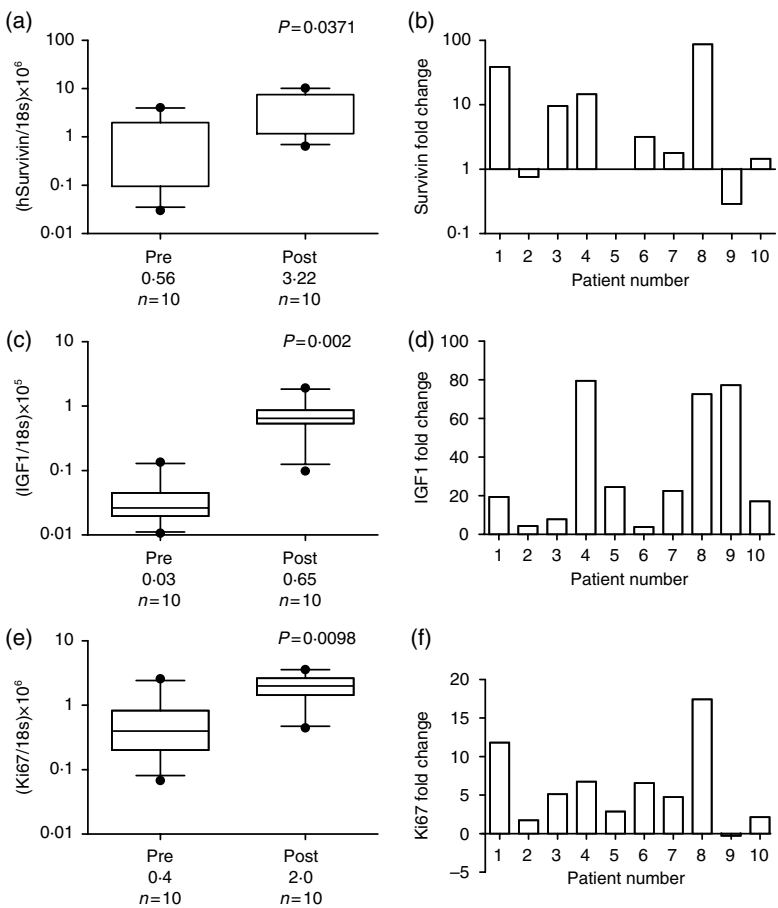

Figure 3 Survivin mRNA expression is increased in the human endometrium after estrogen treatment. RNA samples obtained from endometrial biopsies of ten women at baseline and after 6 months of estrogen treatment were analyzed by QPCR for survivin ( $a$ and b), IGF1 (c and d), and Ki67 (e and f). Data are presented as a median ratio of (transcript/18s rRNA) (a, c, and e) or fold change for each patient post treatment compared to baseline (b, $d$, and $f$ ). Box represents $25-75 \%$ distribution, and whiskers represent $10-90 \%$ range. Wilcoxon signed-rank test was used to determine significance. 
estrogen treatment in the endometrium of postmenopausal women (Westin et al. 2009). To confirm that the women responded to estrogen treatment, we measured transcript levels of nuclear antigen Ki67, a standard marker of proliferation (Hurskainen et al. 2000, Jaroslav et al. 2005, Strick et al. 2007). We determined that while all ten of the post treatment endometrial tissues exhibited estrogen induction of IGF1 (Fig. 3d), only nine of the ten patients responded with a proliferative phenotype indicated by increased Ki67 expression. Notably, patient \# 9, who showed a decrease in Ki67 transcript, also showed a decrease in survivin transcript (Fig. 3f). The fold change in survivin induction significantly correlated with the fold change in Ki67 $\left(P<0 \cdot 0001, r^{2}=0 \cdot 98\right)$ but not with IGF1 fold change $\left(P=0 \cdot 76, r^{2}=0 \cdot 12\right)$, and IGF1 fold change also did not correlate with fold change in $\operatorname{Ki67}\left(P=0 \cdot 758, r^{2}=0 \cdot 11\right)$. The women's age $(P=0 \cdot 73)$, BMI $(P=0 \cdot 89)$, time since last menstrual period $(P=0 \cdot 94)$, baseline serum $\mathrm{E}_{2}(P=0 \cdot 87)$, FSH $(P=0.47)$, and prolactin $(P=0.97)$ levels did not correlate with fold change in survivin expression.

\section{Discussion}

Survivin has been shown by our group and others to be overexpressed in several endometrial disease states including endometriosis, endometrial hyperplasia, and endometrial carcinomas. Information on the role of survivin in maintaining normal tissue homeostasis is lacking. The human endometrium is a classically hormone-responsive tissue; therefore, it is susceptible to endocrine-related pathologies as well as treatments. In this study, we show that survivin transcript expression is significantly increased in the $E_{2}$-predominated proliferative phase, and is significantly decreased in the $\mathrm{P}_{4}$-predominated secretory phase of the normal endometrium. These data are in agreement with those published by Lehner et al. (2002) and suggest that survivin gene expression is hormonally regulated in the human endometrium.

It is enticing to speculate that survivin's anti-apoptotic and cell cycle regulatory functions may be involved in maintaining normal tissue homeostasis; however, it is important to note that our studies examined only survivin gene expression, not survivin protein. Konno et al. (2000) published work indicating that survivin transcript and protein were increased in the secretory phase rather than the proliferative phase of cycling endometrium. While our transcript data are contrary to the Konno et al. results, there are, to our knowledge, no published works that disagree with the Konno et al. protein results. It has been shown that survivin protein is increased by estrogens and decreased by progestins in endometrial cancer-derived cells in vitro; however, further studies will be required to determine whether survivin protein expression is similarly hormonally regulated in disease-free human endometrial tissue. We postulated that the survivin transcript may be functional in the endometrium as it is a natural antisense transcript to the effector cell protease receptor 1 (EPR1). EPR 1 is the receptor for factor $\mathrm{Xa}$ and is involved in vascular inflammation and blood coagulation. Inverse expression of survivin and EPR1 has been observed in several systems and hematologic malignancies. However, QPCR analysis conducted in our laboratory with an EPR1-specific probe could not detect EPR1 transcript neither in normal proliferative human endometrial tissue nor in endometrial tumors (data not shown). We did not examine secretory tissue for EPR 1 gene expression.

We are the first to report that survivin gene expression is changed in response to administration of $\mathrm{E}_{2}$ and $\mathrm{P}_{4}$ in the disease-free human endometrium. A 6-month treatment with $\mathrm{E}_{2}$ significantly increased the expression of a well-known $\mathrm{E}_{2}$-regulated gene, IGF1. In addition, survivin gene expression increased and was associated with increased proliferation indices as measured by Ki67 expression. These data suggest that while the IGF1 protein is functionally involved in mediating the proliferative response towards estradiol, the survivin transcript may be more useful than the IGF1 transcript as an indicator of hormone treatment efficacy, specifically as a marker of proliferation in response to $E_{2}$. A larger study including more women will be necessary to validate this finding.

A 3-month treatment with DEPO resulted in a significant increase in a well-known $\mathrm{P}_{4}$-regulated gene, IGFBP1, and resulted in a significant decrease in the gene expression of survivin. A report published recently indicated that increased survivin protein levels predicted resistance to progestin therapy in patients with endometrial hyperplasia (Chen et al. 2009). In our dataset, upon histological examination, two women were determined to be non-responders to progestin treatment, and both patients also exhibited an aberrant survivin response (no change or increased gene expression) as measured by QPCR. A larger study including more non-responders will be necessary to assess the significance of this finding.

Herein, we report preliminary results suggesting that survivin transcript as a biomarker could be helpful to clinicians who prescribe hormone replacement therapies to postmenopausal women or to those who use hormone therapies as chemopreventive agents in high-risk populations. Larger studies will be needed to validate the utility of survivin transcript as a biomarker for hormone treatment efficacy and/or resistance in these populations.

\section{Declaration of interest}

D S Loose's work has been funded by the NIH and the John S Dunn foundation. He is a consultant for Wyeth Pharmaceuticals for which he receives compensation. The other authors have no conflicts of interest.

\section{Funding}

D S L, A S M and R R B are supported by the NIH SPORE in Endometrial Cancer 1P50CA098258-01; K H L and L-M C are supported by the NCI NO1-CN-05127; H T L is supported by NIH 1U01CA86389, and N H N is supported by the Rosalie B Hite Graduate Student Fellowship. 


\section{Acknowledgements}

We thank Dr James Pickar (Wyeth Research, Philadelphia, Pennsylvania) for generously providing endometrial RNA samples from Premarin-treated women. We thank Dr Greg Shipley (Quantitative Genomics Core Laboratory, University of Texas Medical School, Houston, Texas) for designing the QPCR assays reported. We thank Dr Caimiao Wei for generously providing statistical advice and support.

\section{References}

Ai Z, Yin L, Zhou X, Zhu Y, Zhu D, Yu Y \& Feng Y 2006 Inhibition of survivin reduces cell proliferation and induces apoptosis in human endometrial cancer. Cancer 107 746-756. (doi:10.1002/cncr.22044)

Ambrosini G, Adida C \& Altieri DC 1997 A novel anti-apoptosis gene, survivin, expressed in cancer and lymphoma. Nature Medicine 3 917-921. (doi:10.1038/nm0897-917)

Bell SC, Jackson JA, Ashmore J, Zhu HH \& Tseng L 1991 Regulation of insulin-like growth factor-binding protein-1 synthesis and secretion by progestin and relaxin in long term cultures of human endometrial stromal cells. Journal of Clinical Endocrinology and Metabolism 72 1014-1024. (doi:10.1210/jcem-72-5-1014)

Bischof P, Krahenbuhl C \& Desaulles PA 1974 Elucidation of the mechanism responsible for the luteolytic effect of oestradiol during pseudogestation in the rat. Experientia 30 1101-1102. (doi:10.1007/BF01939032)

Chen X, Zhang Z, Feng Y, Fadare O, Wang J, Ai Z, Jin H, Gu C \& Zheng W 2009 Aberrant survivin expression in endometrial hyperplasia: another mechanism of progestin resistance. Modern Pathology 22 699-708. (doi:10. 1038/modpathol.2009.25)

Deng L, Shipley GL, Loose-Mitchell DS, Stancel GM, Broaddus R, Pickar JH \& Davies PJ 2003 Coordinate regulation of the production and signaling of retinoic acid by estrogen in the human endometrium. Journal of Clinical Endocrinology and Metabolism 88 2157-2163. (doi:10.1210/jc.2002-021844)

Deng L, Broaddus RR, McCampbell A, Shipley GL, Loose DS, Stancel GM, Pickar JH \& Davies PJ 2005 Identification of a novel estrogen-regulated gene, EIG121, induced by hormone replacement therapy and differentially expressed in type I and type II endometrial cancer. Clinical Cancer Research 11 8258-8264. (doi:10.1158/1078-0432.CCR-05-1189)

Fowler DJ, Nicolaides KH \& Miell JP 2000 Insulin-like growth factor binding protein-1 (IGFBP-1): a multifunctional role in the human female reproductive tract. Human Reproduction Update 6 495-504. (doi:10.1093/ humupd/6.5.495)

Fujino K, Ueda M, Takehara M, Futakuchi H, Kanda K, Yamashita Y, Terai Y \& Ueki M 2006 Transcriptional expression of survivin and its splice variants in endometriosis. Molecular Human Reproduction 12 383-388. (doi:10.1093/ molehr/gal042)

Fukuda S \& Pelus LM 2006 Survivin, a cancer target with an emerging role in normal adult tissues. Molecular Cancer Therapeutics 5 1087-1098. (doi:10. 1158/1535-7163.MCT-05-0375)

Gao JG, Mazella J, Powell DR \& Tseng L 1994a Identification of a distal regulatory sequence of the human IGFBP-1 gene promoter and regulation by the progesterone receptor in a human endometrial adenocarcinoma cell line. DNA and Cell Biology 13 829-837. (doi:10.1089/dna.1994.13.829)

Gao JG, Mazella J \& Tseng L 1994b Activation of the human IGFBP-1 gene promoter by progestin and relaxin in primary culture of human endometrial stromal cells. Molecular and Cellular Endocrinology 104 39-46. (doi:10.1016/ 0303-7207(94)90049-3)

Garcia MG, Tirado-Gonzalez I, Handjiski B, Tometten M, Orsal AS, Hajos SE, Fernandez N, Arck PC \& Blois SM 2007 High expression of survivin and down-regulation of Stat-3 characterize the feto-maternal interface in failing murine pregnancies during the implantation period. Placenta 28 650-657. (doi:10.1016/j.placenta.2006.09.010)

Goteri G, Lucarini G, Pieramici T, Filosa A, Pugnaloni A, Montik N, Biagini G, Tranquilli AL, Fabris G, Ciavattini A et al. 2005 Endothelial cell survivin is involved in the growth of ovarian endometriotic cysts. Anticancer Research 25 4313-4318.
Harada T, Kaponis A, Iwabe T, Taniguchi F, Makrydimas G, Sofikitis N, Paschopoulos M, Paraskevaidis E \& Terakawa N 2004 Apoptosis in human endometrium and endometriosis. Human Reproduction Update 10 29-38. (doi:10.1093/humupd/dmh007)

Hurskainen R, Salmi A, Paavonen J, Teperi J \& Rutanen E 2000 Expression of sex steroid receptors and $\mathrm{Ki}-67$ in the endometria of menorrhagic women: effects of intrauterine levonorgestrel. Molecular Human Reproduction 6 1013-1018. (doi:10.1093/molehr/6.11.1013)

Jaroslav P, Martina H, Jiri S, Hana K, Petr S, Tomas K, Julius M \& Cedrik H 2005 Expression of cyclins D1, D2, and D3 and Ki-67 in leukemia. Leukemia and Lymphoma 46 1605-1612. (doi:10.1080/ 10428190500215100)

Kashima H, Shiozawa T, Miyamoto T, Suzuki A, Uchikawa J, Kurai M \& Konishi I 2009 Autocrine stimulation of IGF1 in estrogen-induced growth of endometrial carcinoma cells: involvement of the mitogen-activated protein kinase pathway followed by up-regulation of cyclin D1 and cyclin E. Endocrine-Related Cancer 16 113-122. (doi:10.1677/ERC-08-0117)

Knobil E 1972 Hormonal control of the menstrual cycle and ovulation in the rhesus monkey. Acta Endocrinologica. Supplementum 71 S137-S144. (doi:10. 1530/acta.0.071S137)

Kokawa K, Shikone T \& Nakano R 1996 Apoptosis in the human uterine endometrium during the menstrual cycle. Journal of Clinical Endocrinology and Metabolism 81 4144-4147. (doi:10.1210/jc.81.11.4144)

Konno R, Yamakawa H, Utsunomiya H, Ito K, Sato S \& Yajima A 2000 Expression of survivin and Bcl-2 in the normal human endometrium. Molecular Human Reproduction 6 529-534. (doi:10.1093/molehr/6.6.529)

Lane B, Oxberry W, Mazella J \& Tseng L 1994 Decidualization of human endometrial stromal cells in vitro: effects of progestin and relaxin on the ultrastructure and production of decidual secretory proteins. Human Reproduction 9 259-266.

Lehner R, Enomoto T, McGregor JA, Shroyer L, Haugen BR, Pugazhenthi U \& Shroyer KR 2002 Correlation of survivin mRNA detection with histologic diagnosis in normal endometrium and endometrial carcinoma. Acta Obstetrica et Gynecologica Scandinavica 81 162-167. (doi:10.1034/ j.1600-0412.2002.810213.x)

Li F \& Altieri DC 1999 Transcriptional analysis of human survivin gene expression. Biochemical Journal 344 305-311. (doi:10.1042/02646021:3440305)

Li H, Yang J \& Sun Y 2002 Expression of survivin in early villus and decidua and its implication. Journal of Huazhong University of Science and Technology. Medical Sciences 22 118-120, 170. (doi:10.1007/BF02857670)

Li F, Devi YS, Bao L, Mao J \& Gibori G 2008 Involvement of cyclin D3, CDKN1A (p21), and BIRC5 (Survivin) in interleukin 11 stimulation of decidualization in mice. Biology of Reproduction 78 127-133. (doi:10.1095/ biolreprod.107.063313)

McCampbell AS, Broaddus RR, Loose DS \& Davies PJ 2006 Overexpression of the insulin-like growth factor I receptor and activation of the AKT pathway in hyperplastic endometrium. Clinical Cancer Research 12 6373-6378. (doi:10.1158/1078-0432.CCR-06-0912)

Moyano P \& Rotwein P 2004 Mini-review: estrogen action in the uterus and insulin-like growth factor-I. Growth Hormone and IGF Research 14 431-435. (doi:10.1016/j.ghir.2004.09.001)

Nabilsi NH, Broaddus RR \& Loose DS 2009 DNA methylation inhibits p53-mediated survivin repression. Oncogene 28 2046-2050. (doi:10.1038/ onc.2009.62)

Nakayama Y, Sakamoto H, Satoh K \& Yamamoto T 2000 Tamoxifen and gonadal steroids inhibit colon cancer growth in association with inhibition of thymidylate synthase, survivin and telomerase expression through estrogen receptor beta mediated system. Cancer Letters 161 63-71. (doi:10. 1016/S0304-3835(00)00600-5)

Noyes RW, Hertig AT \& Rock J 1975 Dating the endometrial biopsy. American Journal of Obstetrics and Gynecology 122 262-263.

O'Driscoll L, Linehan R \& Clynes M 2003 Survivin: role in normal cells and in pathological conditions. Current Cancer Drug Targets 3 131-152. (doi:10.2174/1568009033482038)

Pallares J, Martinez-Guitarte JL, Dolcet X, Llobet D, Rue M, Palacios J, Prat J \& Matias-Guiu X 2005 Survivin expression in endometrial carcinoma: a 
tissue microarray study with correlation with PTEN and STAT-3. International Journal of Gynecological Pathology 24 247-253. (doi:10.1097/01. pgp.0000163849.37129.d4)

Richards RG, Brar AK, Frank GR, Hartman SM \& Jikihara H 1995 Fibroblast cells from term human decidua closely resemble endometrial stromal cells: induction of prolactin and insulin-like growth factor binding protein-1 expression. Biology of Reproduction 52 609-615. (doi:10.1095/biolreprod52.3.609)

Rutanen EM 1998 Insulin-like growth factors in endometrial function. Gynecological Endocrinology 12 399-406. (doi:10.3109/0951359 9809012842)

Sayeed A, Konduri SD, Liu W, Bansal S, Li F \& Das GM 2007 Estrogen receptor alpha inhibits p53-mediated transcriptional repression: implications for the regulation of apoptosis. Cancer Research 67 7746-7755. (doi:10.1158/0008-5472.CAN-06-3724)

Strick R, Ackermann S, Langbein M, Swiatek J, Schubert SW, Hashemolhosseini S, Koscheck T, Fasching PA, Schild RL, Beckmann MW et al. 2007 Proliferation and cell-cell fusion of endometrial carcinoma are induced by the human endogenous retroviral Syncytin-1 and regulated by TGF-beta. Journal of Molecular Medicine 85 23-38. (doi:10.1007/s00109-006-0104-y)

Takai N, Miyazaki T, Nishida M, Nasu K \& Miyakawa I 2002 Survivin expression correlates with clinical stage, histological grade, invasive behavior and survival rate in endometrial carcinoma. Cancer Letters 184 105-116. (doi:10.1016/S0304-3835(02)00190-8)

Tarkowski R, Wojcierowski J, Polak G \& Kotarski J 2000 Expression of the survivin gene in normal and hyperplastic endometrium. Ginekologia Polska 71 1226-1229.
Tarkowski R, Kotarski J, Polak G \& Wojcierowski J 2001 Expression of the survivin gene in the scar endometriosis and in normal human endometrium. Ginekologia Polska 72 1539-1542.

Ueda M, Yamashita Y, Takehara M, Terai Y, Kumagai K, Ueki K, Kanda K, Yamaguchi H, Akise D, Hung YC et al. 2002 Survivin gene expression in endometriosis. Journal of Clinical Endocrinology and Metabolism 87 3452-3459. (doi:10.1210/jc.87.7.3452)

Vaskivuo TE, Stenback F, Karhumaa P, Risteli J, Dunkel L \& Tapanainen JS 2000 Apoptosis and apoptosis-related proteins in human endometrium. Molecular and Cellular Endocrinology 165 75-83. (doi:10.1016/S03037207(00)00261-6)

Westin SN, Broaddus RR, Deng L, McCampbell A, Lu KH, Lacour RA, Milam MR, Urbauer DL, Mueller P, Pickar JH et al. 2009 Molecular clustering of endometrial carcinoma based on estrogen-induced gene expression. Cancer Biology \& Therapy 8 2126-2135.

Xie R, Loose DS, Shipley GL, Xie S, Bassett RL Jr \& Broaddus RR 2007 Hypomethylation-induced expression of S100A4 in endometrial carcinoma. Modern Pathology 20 1045-1054. (doi:10.1038/modpathol.3800940)

Received in final form 5 August 2010

Accepted 26 August 2010 Made available online as an Accepted Preprint 26 August 2010 